University for Business and Technology in Kosovo

UBT Knowledge Center

UBT International Conference

2018 UBT International Conference

Oct 27th, $10: 45$ AM - 12:15 PM

\title{
Exergetic Analysis of a Cogeneration System for Cooling and Heating
}

\author{
Alexandru Serban \\ University Politehnica of Bucharesti \\ Mariana-Florentina Stefanescu \\ University Politehnica of Bucharesti \\ Liviu Drughean \\ Technical University for Civil Engineering of Bucharest \\ Gabriel Nastase \\ University Transilvania of Brasov \\ Mihaela Ciocan \\ University Politehnica of Bucharesti
}

See next page for additional authors

Follow this and additional works at: https://knowledgecenter.ubt-uni.net/conference

Part of the Engineering Commons

\section{Recommended Citation}

Serban, Alexandru; Stefanescu, Mariana-Florentina; Drughean, Liviu; Nastase, Gabriel; Ciocan, Mihaela; Bucsa, Sorin; and Dobrovicescu, Alexandru, "Exergetic Analysis of a Cogeneration System for Cooling and Heating" (2018). UBT International Conference. 150.

https://knowledgecenter.ubt-uni.net/conference/2018/all-events/150

This Event is brought to you for free and open access by the Publication and Journals at UBT Knowledge Center. It has been accepted for inclusion in UBT International Conference by an authorized administrator of UBT Knowledge Center. For more information, please contact knowledge.center@ubt-uni.net. 


\section{Presenter Information}

Alexandru Serban, Mariana-Florentina Stefanescu, Liviu Drughean, Gabriel Nastase, Mihaela Ciocan, Sorin Bucsa, and Alexandru Dobrovicescu 


\title{
Exergetic Analysis of a Cogeneration System for Cooling and Heating
}

\author{
Alexandru Serban ${ }^{1}$, Mariana-Florentina Stefanescu ${ }^{1}$, Liviu Drughean ${ }^{2}$, \\ Gabriel Nastase $^{3}$, Mihaela Ciocan ${ }^{1}$, Sorin Bucsa ${ }^{1}$, Alexandru Dobrovicescu ${ }^{1}$ \\ ${ }^{1}$ University Politehnica of Bucharesti, Splaiul Independentei 313, Sector 6, 060042, Bucharest, \\ Romania \\ ${ }^{2}$ Technical University for Civil Engineering of Bucharest, Bd. Lacul Tei 122, Sector 2, 020396 \\ Bucharest, Romania \\ ${ }^{3}$ University Transilvania of Brasov, Bulevardul Eroilor 29, Brașov 500036, Romania \\ adobrovicescu@yahoo.com
}

\begin{abstract}
The paper deals with a heat pump system for the food industry characterized by two products - refrigeration and heating. The working fluid is ammonia, an ecological refrigerant harmless for the environment. For every apparatus, corresponding to its utility and operating field, the exergetic balance states the "product" and "fuel". The work analyses the conduct of the system at the variation of the operating and constructive parameters.. The exergoeconomic technique succeeds in pointing out for every dissipative zone the exergy destruction and losses.
\end{abstract}

Keywords: Cogeneration heating and cooling, Exergy analysis, Exergy destruction, Fuel and product 


\section{Introduction}

When two products are generated in the same time and in the same unit the energetic efficiency of the system becomes very high.

When the products are electrical/mechanical energy and heat or both products are quantities of heat at different temperature levels an exergetic analysis is imposed. The optimization of dual purpose systems is an attractive topic.

Tamer Yilmaz [1] studied a cogeneration system undergoing an internal reversible Carnot cycle with external irreversibilities.

Hisham S. Bamufleh et al. [2] applied a multi-objective procedure for the optimization of a cogeneration unit. The economic and environmental impacts were taken into account. The analysis is performed using a genetic algorithm.

P.K.Sahoo [3] presents an optimization case based on evolutionary programming.

In the present work, by properly defining the "Fuel" and "Product" of the key parts of the cooling and heating system, the analysis gets closer to reality offering better insights for optimization.

\section{System Flow Diagram}

Consider a heat-pump system that offers two products - heating and cooling. To quantify the useful effect of each one of the two products the analysis is based on the exergy concept.

Figure 1 shows the flow chart and p-h diagram of the considered system.

The working fluid is R717 (NH3). The cold and hot carrying fluid, in the evaporator and condenser, is water. Compressors and pumps are characterized by an isentropic efficiency $\eta_{\mathrm{s}}=0.8$

The shell and tube condenser has an estimated pressure drop $\Delta \mathrm{p}_{\mathrm{c}}=22 \mathrm{kPa}$ and a minimum temperature difference between fluids $\Delta t_{c}=5 \mathrm{~K}$.

The evaporator is a plate heat exchanger characterized by a pressure loss $\Delta p_{v}=46$ $\mathrm{kPa}$ and a minimum temperature difference between fluids $\Delta \mathrm{t}_{\mathrm{v}}=3 \mathrm{~K}$.

The COP of the system is high due to the two products it delivers.

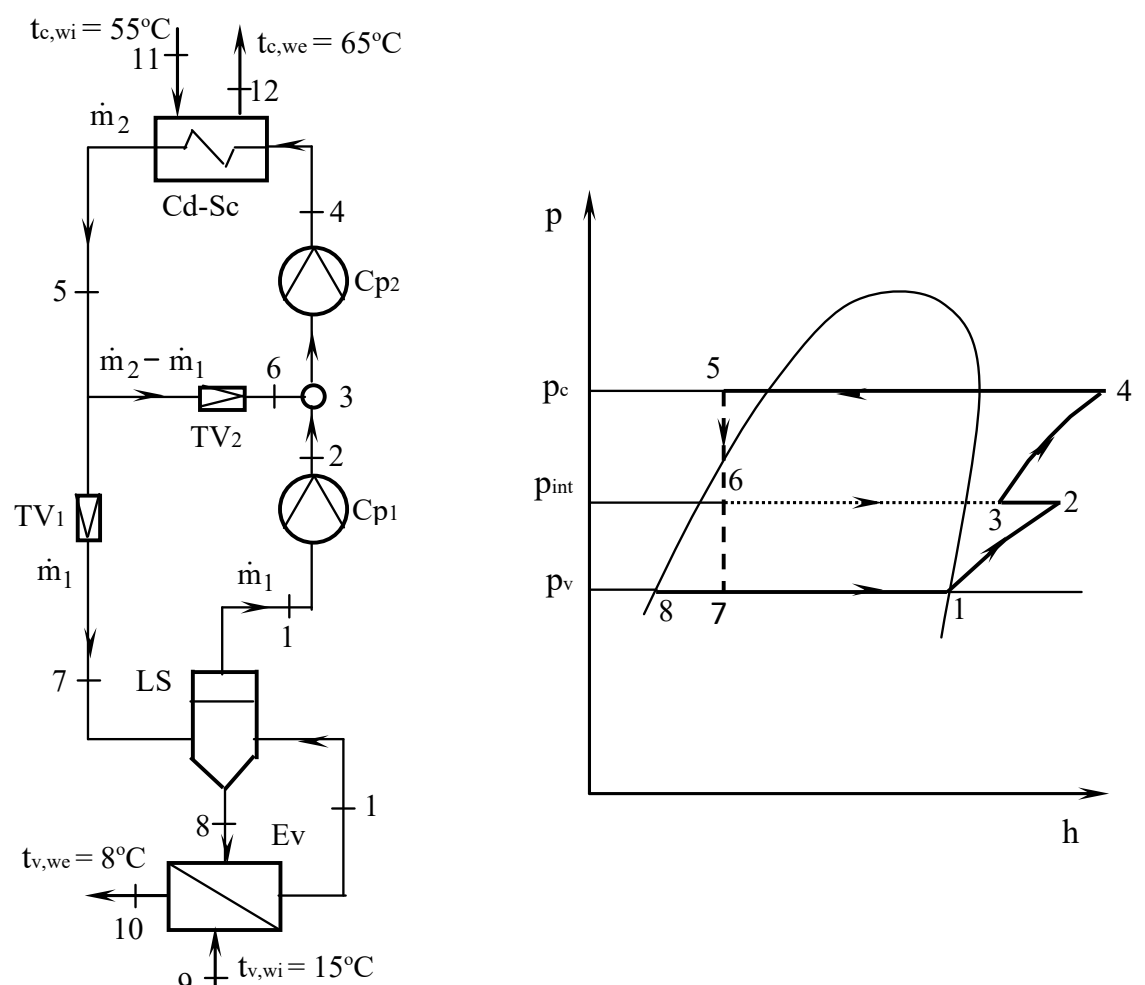


Fig. 1 Heat pump system: (a) flow diagram ; (b) p-h diagram

\section{Exergetic Balance}

The analysis has been achieved at the customer level.

The utility the system offers to the customer, namely the system product $\mathrm{P}$, is the sum of the heat exergies extracted in the evaporator $\left|\dot{\mathrm{E}} \mathrm{Q}_{\mathrm{Qv}}^{\mathrm{T}_{\mathrm{v}}}\right|$ or delivered in the condenser $\left|\dot{\mathrm{E} x} \mathrm{Qc}_{\mathrm{C}, \mathrm{w}}^{\mathrm{T}}\right|$.

To specify the system exergy losses and destruction, the evaporator and condenser have been separately analyzed.

\subsection{The Evaporator}

The operating scheme of the evaporator is given in Fig.2

The energetic balance equation on the cold carrying agent side gives:

$$
\dot{\mathrm{Q}}_{\mathrm{v}}=\Delta \dot{\mathrm{H}}=\dot{\mathrm{m}}_{\mathrm{v}, \mathrm{w}}\left(\mathrm{h}_{10}-\mathrm{h}_{9}\right)=\dot{\mathrm{m}}_{\mathrm{v}, \mathrm{w}}\left[\mathrm{c}_{\mathrm{v}, \mathrm{w}}\left(\mathrm{t}_{10}-\mathrm{t}_{9}\right)+\mathrm{v}_{\mathrm{v}, \mathrm{w}}\left(\mathrm{p}_{10}-\mathrm{p}_{9}\right)\right]
$$

Considering that line 9-10 includes the pump that runs the cold carrying agent, and that $p_{10}-p_{9}=\Delta p_{v, P}+\Delta p_{v}=\frac{\Delta p_{v}}{\eta_{s}}$, where $\Delta p_{v, P}=\Delta p_{v}\left(\frac{1}{\eta_{s}}-1\right)$ represents the additional pressure increase necessary to overcome the internal pump friction, Eq.1 becomes:

$$
\dot{\mathrm{Q}}_{\mathrm{v}}=\dot{\mathrm{m}}_{\mathrm{v}, \mathrm{w}}\left[\mathrm{c}_{\mathrm{v}, \mathrm{m}}\left(\mathrm{t}_{10}-\mathrm{t}_{9}\right)+\frac{\mathrm{v}_{\mathrm{v}, \mathrm{m}} \cdot \Delta \mathrm{p}_{\mathrm{v}}}{\eta_{\mathrm{s}}}\right]
$$

It can be noticed that the pressure loss due to friction on the cold carrying agent side leads to an increase in its temperature at the outlet from the evaporator

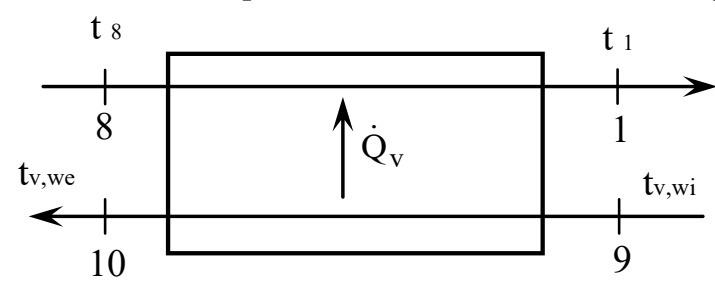

Fig. 2 Evaporator 
Defining for the evaporator, in exergetic terms, the product $\mathrm{P}_{\mathrm{v}}$ and the resources $F_{v}$ consumed to make it (generically the "fuel" of the evaporator), the exergetic balance equation written with an economic tint becomes:

$$
\dot{\mathrm{F}}_{\mathrm{v}}=\dot{\mathrm{P}}_{\mathrm{v}}+\dot{\mathrm{L}}_{\mathrm{v}}+\dot{\mathrm{I}}_{\mathrm{v}}
$$

The thermal part of the total exergy of the cooling power $\left(\dot{E x}^{\mathrm{T}}\right)$ at the costumer temperature is the product of the evaporator.

$$
\dot{\mathrm{P}}_{\mathrm{v}}=\dot{\mathrm{E}} \mathrm{x}_{10}^{\mathrm{T}}-\dot{\mathrm{E}} \mathrm{x}_{9}^{\mathrm{T}}=\dot{\mathrm{m}}_{\mathrm{v}, \mathrm{w}} \cdot \mathrm{c}_{\mathrm{v}, \mathrm{w}}\left[\left(\mathrm{t}_{10}-\mathrm{t}_{9}\right)-\mathrm{T}_{0} \ln \frac{\mathrm{T}_{10}}{\mathrm{~T}_{9}}\right]
$$

For the same apparatus the total exergy ( $\dot{\mathrm{Ex}}^{\mathrm{TOT}}$ ) consumed by the refrigerant represents the Fuel.

$$
\begin{aligned}
& \dot{\mathrm{F}}_{\mathrm{v}}=\left(\dot{\mathrm{Ex}}_{8}^{\mathrm{TOT}}-\dot{\mathrm{Ex}}_{1}^{\mathrm{TOT}}\right)+\left(\dot{\mathrm{E}} \mathrm{x}_{9}^{\mathrm{M}}-\dot{\mathrm{Ex}}_{10}^{\mathrm{M}}\right)=\dot{\mathrm{m}}_{1}\left[\mathrm{~h}_{8}-\mathrm{h}_{1}-\mathrm{T}_{0}\left(\mathrm{~s}_{8}-\mathrm{s}_{1}\right)\right]+ \\
& +\frac{\dot{\mathrm{m}}_{\mathrm{v}, \mathrm{w}} \cdot \mathrm{v}_{\mathrm{v}, \mathrm{w}} \cdot\left|\Delta \mathrm{p}_{\mathrm{v}}\right|}{\eta_{\mathrm{s}}}
\end{aligned}
$$

Accounting for the exergy loss due to the imperfect mechanical transmission from the electrical motor to the water pump and for the heat transferred by the electrical motor to its ambient medium, the loss associated to the pump operating becomes:

$$
\dot{\mathrm{L}}_{\mathrm{v}, \mathrm{P}}=\frac{\dot{\mathrm{m}}_{\mathrm{v}, \mathrm{w}} \cdot \mathrm{v}_{\mathrm{v}, \mathrm{w}} \cdot\left|\Delta \mathrm{p}_{\mathrm{v}}\right|}{\eta_{\mathrm{s}} \cdot \eta_{\mathrm{m}} \cdot \eta_{\mathrm{el}}}
$$

The exergy destruction due to friction in the evaporator on the water side is the sum of the mechanical work input of the pump and the exergy of the heat generated by friction.

$$
\dot{\mathrm{L}}_{\mathrm{v}, \mathrm{f}}=\frac{\dot{\mathrm{m}}_{\mathrm{v}, \mathrm{w}} \cdot \mathrm{v}_{\mathrm{v}, \mathrm{w}} \cdot\left|\Delta \mathrm{p}_{\mathrm{v}}\right|}{\eta_{\mathrm{s}}}\left(\frac{\mathrm{T}_{0}}{\mathrm{~T}_{\mathrm{v}, \mathrm{w}}}-1\right)
$$

The exergy destruction due to heat transfer across a temperature difference in the evaporator is:

$$
\dot{\mathrm{I}}_{\mathrm{v}, \Delta \mathrm{T}}=\dot{\mathrm{Q}}_{01} \cdot \mathrm{T}_{0} \frac{\mathrm{T}_{\mathrm{v}, \mathrm{w}}-\mathrm{T}_{\mathrm{v}}}{\mathrm{T}_{\mathrm{v}, \mathrm{w}} \cdot \mathrm{T}_{\mathrm{v}}}
$$

\subsection{Condenser}

For the condenser of the heat pump the exergy of the heat friction is recovered and added to the zonal product $P_{c}$. The anergy of this heat represents the mechanical energy (exergy) destruction due to the irreversibility of friction $\dot{\mathrm{I}}_{\mathrm{c}, \mathrm{f}}$. 
The exergy balance of the cogeneration system is:

$$
\begin{aligned}
& \left|\dot{\mathrm{W}}_{\mathrm{cp} 1, \mathrm{t}}\right|+\left|\dot{\mathrm{W}}_{\mathrm{cp} 2, \mathrm{t}}\right|+\left|\dot{\mathrm{W}}_{\mathrm{P} 1, \mathrm{t}}\right|+\left|\dot{\mathrm{W}}_{\mathrm{P} 2, \mathrm{t}}\right|=\left(\dot{\mathrm{Ex}}_{10}^{\mathrm{T}}-\dot{\mathrm{E}}_{9}^{\mathrm{T}}\right)+\left(\dot{\mathrm{Ex}}_{12}^{\mathrm{T}}-\dot{\mathrm{Ex}}_{11}^{\mathrm{T}}\right)+\dot{\mathrm{I}}_{\mathrm{cp} 1}+ \\
& +\dot{\mathrm{L}}_{\mathrm{cp} 1, \mathrm{~m}, \mathrm{el}}+\dot{\mathrm{I}}_{\mathrm{cp} 2}+\dot{\mathrm{L}}_{\mathrm{cp} 2, \mathrm{~m}, \mathrm{el}}+\dot{\mathrm{I}}_{\mathrm{c}, \mathrm{f}}+\dot{\mathrm{I}}_{\mathrm{c}, \Delta \mathrm{T}}+\dot{\mathrm{L}}_{\mathrm{c}, \mathrm{P}}+\dot{\mathrm{I}}_{\mathrm{t} 1}++\dot{\mathrm{I}}_{\mathrm{t} 2}+\dot{\mathrm{I}}_{\mathrm{v}, \Delta \mathrm{T}}+ \\
& +\dot{\mathrm{L}}_{\mathrm{v}, \mathrm{f}}+\dot{\mathrm{L}}_{\mathrm{v}, \mathrm{P}}
\end{aligned}
$$

Based on energetic and exergetic balance equations, the refrigerating and heating system coefficients of performance become:

$$
\eta_{\mathrm{t}}=\frac{\left|\dot{\mathrm{Q}}_{01}\right|+\left|\dot{\mathrm{Q}}_{\mathrm{c} 1}\right|}{\sum \dot{\mathrm{W}}_{\mathrm{t}}} \quad(10) \quad \eta_{\mathrm{ex}}=\frac{\Delta \dot{\mathrm{Ex}}_{\mathrm{v}}^{\mathrm{T}}+\Delta \dot{\mathrm{Ex}}_{\mathrm{c}}^{\mathrm{T}}}{\sum \dot{\mathrm{W}}_{\mathrm{t}}}
$$

\section{Influence of the Variation of the Operating Parameters}

The temperature levels for cooling and heating on the costumer side are given by the project (Fig. 1).

The intermediary pressure will be stated based on an optimization criterion.

The maximization of the coefficients of performance is presented in figure 3.

It can be noticed that intermediary pressure $p_{2}=1.5 \mathrm{MPa}$ approximately corresponds to both maximum energetic and exergetic efficiency.

When the temperature level of the thermal agent that takes away the heat in the condenser is kept constant, the increase in the condensation temperature $T_{c}$ and implicitly in the temperature difference in the condenser, leads to the decrease in the condenser conductance $K_{c}$ and consequently in its investment cost (figure 4).

The decrease in the investment cost of the condenser is accompanied by the quick decrease in the thermal efficiency $\eta_{t}$.

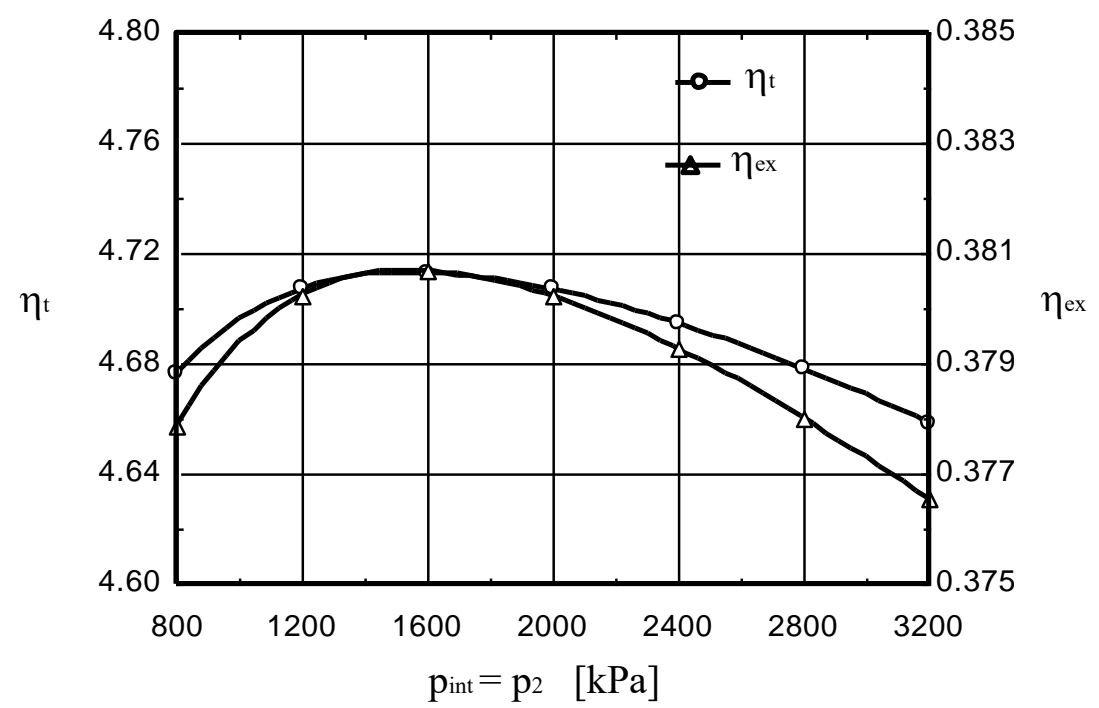


Fig. 3 Plot of energetic and exergetic efficiency against the intermediary pressure

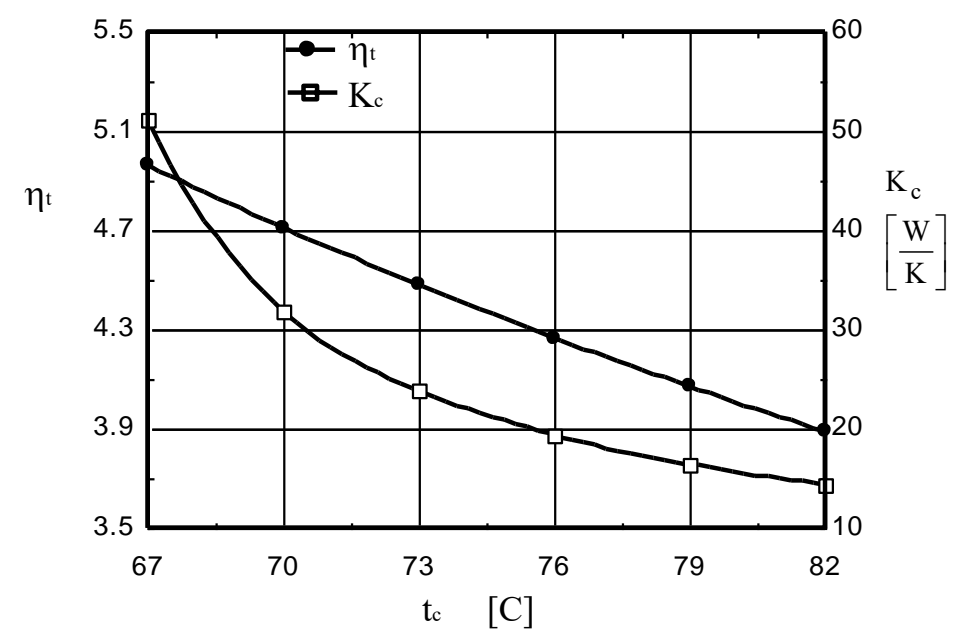

Fig. 4 Plot of the thermal efficiency and thermal conductance against the condensation temperature $T_{c}$

\section{Conclusion}

The exergetic balance of the system states for each one of the apparatuses its "product" and "fuel". For each dissipative zone the exergy losses and destruction are pointed out.

For the vaporizer the exergy of the heat generated in the friction process has to be removed by the refrigeration system increasing in this way the input power of the compressor.

For the condenser the anergy of the heat generated by friction represents an exergy destruction due to friction irreversibility.

The work states the optimum intermediary pressure at which the system reaches maximum values for its coefficients of performance.

The variation in the thermal conductance and in the related heat exchangers investment cost, at the variation in the average temperature difference in the apparatuses, is discussed. 


\section{References}

1. Yilmaz, T., :Optimization of cogeneration systems under alternative performance criteria, Energy Conversion and Management, Volume 45, Issue 6, (2004) 939-945

2. Bamufleh, S.H., Ortega, J.M.P., El-Halwagi, M.M., Multi-objective optimization of process cogeneration systems with economic, environmental, and social tradeoffs, Clean Technologies and Environmental Policy, Volume 15, Issue 1, (2013) 185-197

3. Sahoo, P.K., Exergoeconomic analysis and optimization of a cogeneration system using evolutionary programming, Applied Thermal Engineering, Volume 28, Issue 13, (2008) $1580-1588$ 